\title{
Comparison Of Immunonephelometric And Immunoturbidimetric Methods for Measuring Beta 2-Microglobulin: Fit for Purpose in Routine Clinical Laboratories
}

Sedefgul Yuzbasioglu Ariyurek ${ }^{1}$, Ozlem Goruroglu Ozturk ${ }^{1,2 *}$, Filiz Kibar ${ }^{1}$, Esin Damla Ziyanoglu Karacor ${ }^{2}$, Gulhan Sahin ${ }^{2}$, Gulay Sezgin ${ }^{3}$ and Akgun Yaman ${ }^{1}$

${ }^{1}$ Cukurova University, Balcali Hospital, Central Laboratory, Adana, Turkey

${ }^{2}$ Cukurova University, Faculty of Medicine, Department of Clinical Biochemistry, Adana, Turkey

${ }^{3}$ Cukurova University, Faculty of Medicine, Department of Pediatric Hematology and Oncology, Adana, Turkey

\begin{abstract}
Serum free beta 2-microglobulin (b2M) level has been regarded as an independent biomarker in several cancers, and has traditionally been analyzed using methods such as Immunonephelometry on specialized analyzers. It is now possible to perform this test on clinical chemistry analyzers, using immunoturbidimetry. The aim of this study was to compare these two methods, for measuring serum b2M level. Fourty three samples which were randomly chosen from sera of patients with various malignant conditions were analyzed for serum b2M level, both by immunonephelometric method in Beckman Immage 800 (Beckman Coulter Inc., CA, USA) nephelometer, and by immunoturbidimetric method in Beckman UniCel DXC 800 Synchron (Beckman Coulter Inc., CA, USA) auto-analyzer. Method comparison demonstrated good agreement between the immunonephelometric and immunoturbidimetric b2M testing, in which we found good correlation $(r=0.973)$ and high accuracy (slope=1.009). As a conclusion, Beckman UniCel DXC 800 Synchron immunoturbidimetric b2M assay is suitable for routine use, and correlates well with representative immunonephelometric assays on the Beckman Immage 800 analyzer. The ability to perform specific protein analyses such as b2M on an integrated clinical chemistry/immunoassay system, can allow consolidation of testing on a single platform and results in improved laboratory operations efficiency. It is thought that immunoturbidimetric method can be used safely in the routine screening of serum b2M level, for different types of malignancies.
\end{abstract}

Keywords: Beta 2-Microglobulin; Immunonephelometry; Immunoturbidimetry; Method Comparison

\section{Introduction}

Beta 2-microglobulin (b2M) is a nonglycosylated protein with a molecular mass of $11,800 \mathrm{Da}$. It forms the beta chain of the human leukocyte antigen (HLA) class I molecule through noncovalent linkage on cell surfaces, and has a 7-stranded beta-pleated structure. Because it is noncovalently associated with the alpha chain of MHC class I molecules and has no direct attachment to the cell membrane, b2M on the cell surface can exchange with free soluble b2M. Free b2M is found in body fluids (including serum, urine, and synovial fluid), as a result of shedding from cell surfaces or intracellular release [1-3]. Approximately, $100-300 \mathrm{mg}$ of b2M is synthesized on a daily basis, i.e. 2-4 mg per kg of body weight [4].

The determination of $\mathrm{b} 2 \mathrm{M}$ in serum or plasma is an aid in the clinical assessment of activation of the cellular immune system and a tumor marker [5]. Recent studies demonstrated that b2M is extensively involved in the functional regulation of immunity, survival, proliferation, apoptosis and even metastasis in cancer cells [5-9]. b2M protein is present at low levels in serum, urine and other body fluids under normal physiological conditions, and is almost exclusively catabolized within the kidney. Many studies have demonstrated that serum or urine b2M concentration is increased in a variety of abnormal cell growth diseases, including breast cancer, prostate cancer, lung cancer, renal cancer, gastrointestinal and nasopharyngeal cancers, multiple myeloma and especially lymphocytic malignancies such as non-Hodgkin's lymphoma and multiple myeloma [10-16]. In these malignancies, the b2M test serves as an independent and significant prognostic factor [17] and it is a helpful indicator for disease development and therapy estimation. Additionally, elevated serum concentrations of b2M are seen with dysfunction of renal glomeruli, while disorders affecting epithelial cells of the proximal tubules will cause an enhanced excretion of this protein in the urine [18-20]. In all these clinical conditions, using sensitive methods are essential to analyze b2M.

Specific proteins have traditionally been analyzed using methodologies, such as Immunonephelometry on specialized analyzers. Immunonephelometry is a well recognized and accepted methodology, but it requires a specialized analyzer that performs a limited menu of tests. A variety of immunoturbidimetric assays are now available, and can be adapted to general purpose clinical chemistry analyzers that are "Open Systems" [21]. Immunoturbidimetric assays have been improved considerably over time. These improvements include advances in antibody purification techniques, enhancements in instrument design and function and production of new reference materials based on global standardization initiatives [22-26]. Additional practical advantages of immunoturbidimetric protein assays include random access analysis instead of batch testing, relatively rapid turn around time, high volume testing capability, cost reduction through consolidation of testing on a single platform, elimination of stand alone

*Corresponding author: Ozlem Goruroglu Ozturk, Medical Biochemistry, Cukurova Universitesi, Cukurova University, A.D. 01330 Adana, Turkey, Tel: +90 506264 2268; Fax: +90 322338 6943; E-mail: ozlem_goruroglu@yahoo.com

Received September 20, 2012; Accepted October 04, 2012; Published October 08, 2012

Citation: Ariyurek SY, Ozturk OG, Kibar F, Ziyanoglu Karacor ED, Sahin G, et al. (2012) Comparison Of Immunonephelometric And Immunoturbidimetric Methods for Measuring Beta 2-Microglobulin: Fit for Purpose in Routine Clinical Laboratories. Biochem Anal Biochem 1:119. doi:10.4172/2161-1009.1000119

Copyright: ( 2012 Ozturk OG, et al. This is an open-access article distributed under the terms of the Creative Commons Attribution License, which permits unrestricted use, distribution, and reproduction in any medium, provided the original author and source are credited. 
Citation: Ariyurek SY, Ozturk OG, Kibar F, Ziyanoglu Karacor ED, Sahin G, et al. (2012) Comparison Of Immunonephelometric And Immunoturbidimetric Methods for Measuring Beta 2-Microglobulin: Fit for Purpose in Routine Clinical Laboratories. Biochem Anal Biochem 1:119. doi:10.4172/2161-1009.1000119

Page 2 of 4

specialized analyzers, and time and effort required to maintain them [21]. Collectively, these characteristics of immunoturbidimetric assays have resulted in more reliable tests and reduced laboratory variances to help clinicians.

b2M test has become a high volume test in clinical laboratories due to its increasing clinical use. Although it has multiple clinical uses, it is measured by only a few automated instruments. Clinical laboratories are under increasing pressure to select the best method, to provide large volumes of high quality analyses in shorter turnaround-times and at the lowest possible cost. Thus, this study was designed to make a method comparison for serum b2M levels, by using immunonephelometric method in Beckman Immage 800 nephelometer and immunoturbidimetric method in Beckman UniCel DXC 800 Synchron auto-analyzer.

\section{Materials and methods}

\section{Collection of specimens}

Randomly chosen serum samples of 43 patients with various malignant conditions, which were referred to the Central Laboratory of Cukurova University Balcali Hospital, (Adana, Turkey) from different clinics in 2011 were included in this study. Serum samples were stored at $70^{\circ} \mathrm{C}$ before being assayed. Patient ages ranged between 9-77.

\section{Immunoassays}

Serum b2M level of all samples were analyzed concurrently, both by immunonephelometric method in Beckman Immage 800 (Beckman Coulter Inc., CA, USA) nephelometer and by immunoturbidimetric method in Beckman UniCel DXC 800 Synchron (Beckman Coulter Inc., CA, USA) auto-analyzer. Additionally, total of 43 specimens were analayzed two times by both methods. Sentinel reagents were used to perform b2M testing on Beckman Immage 800 nephelometer (Ref:A09445 Sentinel Diagnostics, Milan, Italy) and Beckman UniCel DXC 800 Synchron auto-analyzer (Ref:11505H, Sentinel Diagnostics, Milan, Italy).

The Beckman Immage 800 performs non-competitive rate nephelometric assays, in which a polyclonal rabbit anti-human b2M is covalently coupled to polystyrene particles of uniform size. A reaction between these immunoparticles and b2M molecules in the patient specimen, results in the formation of agglutinates that produce changes in the instrument response. b2M concentration is determined by interpolation on a calibration curve.

Turbidimetric b2Mkit is a latex immunoassay, developed to measure b2M levels in serum and urine samples by immunoturbidimetric method. When an antigen-antibody reaction occurs between b2M in a sample and an anti-b2M antibody which has been adsorbed to latex particles, agglutination results. This agglutination is detected as a change in absorbance, with the magnitude of the change being proportional to the quantity of $\mathrm{b} 2 \mathrm{M}$ contained in the sample.

One analyst performed all the analyses, employing the same batches of reagent, quality control material and calibrators. Control material was included in each analytical series to guarantee that analytical imprecision was within the acceptable limits, according to our internal quality control protocol. In addition, external quality assurance program (Bio-Rad Program, California USA) was applied to b2M test, during the period of the study.

\section{Linearity and detection limit}

Linearity studies were performed using blends of samples with different b2M concentrations, that fell within the lower and upper limits of the calibration range. The resultant pools (consisting of 12 points) were assayed in duplicate, using the assay's normal sample volume settings. The observed mean concentration was plotted vs. the expected concentration, and data were examined by linear regression and visual inspection of the bias plots.

The lower limit of detection was defined as the lowest protein concentration corresponding to the mean absorbance value, plus 3 SDs of 10 repeated measurements of the sample diluent [24].

\section{Data analysis}

All results were examined by Bland-Altman analysis and then evaluated by MedCalc software. Correlation relations of both methods were analysed by Pearson correlation analysis, and regression equavalances were analysed by Passing-Bablock regression analysis. SPSS-13.00 (Statistical Package for Social Sciences, Chicago, USA) was used for the whole statistical analyses.

\section{Results}

Results of b2M levels of 43 patients which were measured both in Beckman Immage 800 and Beckman UniCel DXC 800, were analysed by Bland-Altman analysis and the plots of difference against mean for both methods is given in figure 1 .

In the graphics, differences were seen to be randomly collected around zero, and $95 \%$ of it were between $d \pm 1,96$ sd and no relation was found between the differences and means. Mean of the differences and standard deviation were found as 0.22 and 0.607 , respectively. It has been designated that the result of b2M measured by the immunoturbidimetric method, could be either $1.41 \mathrm{mg} / \mathrm{L}$ higher or $0.97 \mathrm{mg} / \mathrm{L}$ lower than the results attained by the immunonephelometric method, and results of two methods were concordant.

According to the results of two methods, the mean and standard deviation attained by the Beckman UniCel DXC 800 and Beckman Immage 800 devices were $2.74 \pm 1.84 \mathrm{mg} / \mathrm{L}$ and $2.96 \pm 2.22 \mathrm{mg} / \mathrm{L}$,

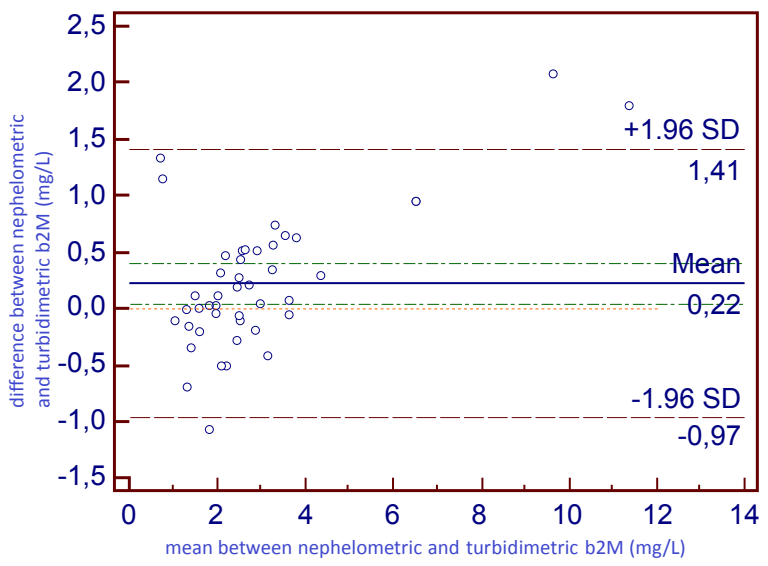

Figure 1: Bland-Altman plot of b2M by the turbidimetry and nephelometry. The $X$ axis indicates the arithmetic mean between the values of b2M by turbidimetry and nephelometry in each patient; the $Y$ axis indicates the difference between the values of b2M by turbidimetry and nephelometry in each patient. 
Citation: Ariyurek SY, Ozturk OG, Kibar F, Ziyanoglu Karacor ED, Sahin G, et al. (2012) Comparison Of Immunonephelometric And Immunoturbidimetric Methods for Measuring Beta 2-Microglobulin: Fit for Purpose in Routine Clinical Laboratories. Biochem Anal Biochem 1:119. doi:10.4172/2161-1009.1000119

respectively. There was a significant (at the $\mathrm{p}=0.01$ level $(\mathrm{r}=0.973)$ ), and acceptable relation between two analyses performed by correlation and regression analyses. The regression equivalance between two methods was $y=1.176 \mathrm{x}-0.263$, and regression standard error was 0.52 . Scatterplots of the results obtained by both methods are given in Goure 2 .

\section{Discussion}

b2M is found to act similarly as a prototypical oncogenic factor, capable of stimulating growth and progression of various cancers and plays a key regulatory role in stimulating cancer metastasis [17]. Free b2M level in serum has been regarded as an independent biomarker in several cancers and has been used to stage diseases, and serial measurements of this protein are used for monitoring response to therapy [27]. Although b2M has multiple clinical uses, it is measured by only a few automated instruments. This study was designed to compare immunonephelometric and immunoturbidimetric methods for analyzing serum b2M levels, to ensure that the performance of immunoturbidimetric assay could be acceptable for clinical needs and fit for purpose.

There was good correlation $(\mathrm{r}=0.973)$ and high accuracy (slope $=1.009$ ) between Beckman UniCel DXC 800 and Beckman Immage 800 assays. This is perhaps because both methods share the same physical principle (scattering) to measure the antigen-antibody complexes. Note however, the Beckman UniCel DXC 800 assay relies on the principle of turbidimetry, which is dependent on scattering and then absorption. Additionally. the assays were found to be linear over the calibration range and the analytical sensitivity consistent with previously described findings for serum proteins [24]. High correlation coefficient indicates that specimens used to compare the two methods cover the range of the assay. The method comparison results were analysed using Passing-Bablok approach, where the results did not depend on the assignment of the methods specific to X or Y. Since Passing-Bablok plot is insensitive to outliers, the scaled median absolute deviation was calculated, which is similar to the standard error of estimate (0.52).

There are many studies in the literature which compared the results of different spesific proteins, such as CRP, IgA, IgG, IgM, C3, C4, haptoglobin, transferin, apolipoproteins, RF etc. held by nefelometric and turbidimetric methods, and results of two methods were found

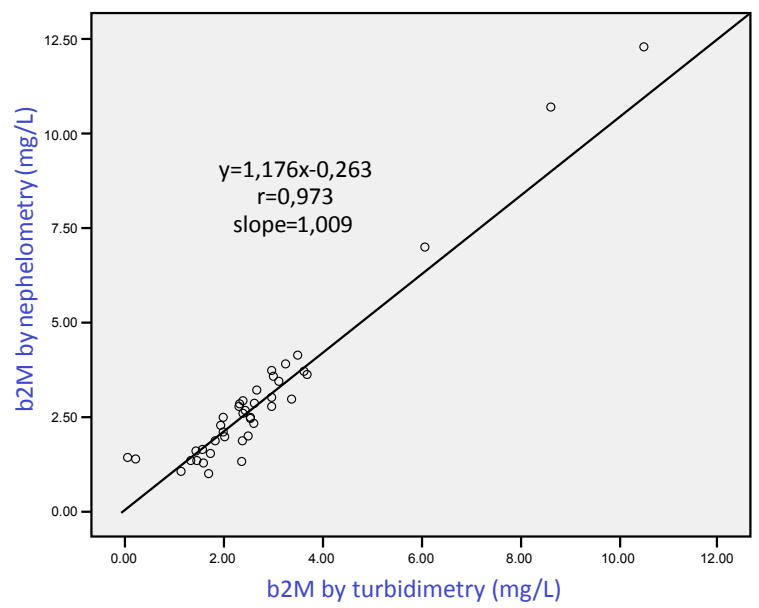

Figure 2: Scatter-plots for the method comparison study between the immunonephelometric and immunoturbidimetric methods. The solid line indicates the line of identity $(\mathrm{x}=\mathrm{y})$. to be correlated with each other [21,28-32]. Correia et al. [28] found that CRP levels measured by either methods were correlated with each other, in both unstable angina patients and in patients with non-ST elevation acute myocardial infarction. In Dominici et al. [30] study, the two systems were found to perform substantially equally, both in hsCRP and in CRP measurement; but in the hsCRP assay, the precision of nephelometry (CV\% in the interval 3.0-5.8) was lower than that of turbidimetry (CV\% in the interval 1.8-2.3). The classification of results by the two methods into three predefined relative risk classes gave $18 \%$ rate of discordance, in any case by one class only. In their study, the two methods proved reliable and comparable in the measurement of hsCRP, and they mention that precision should be improved. Denham et al. [29] demonstrated that by their performance characteristics, the Architect ci8200 immunoturbidimetric specific protein assays are suitable for routine use, and correlate well with representative immunonephelometric assays on the Beckman Immage analyzer. In a study of Ledue et al. [25], in which they evaluated the method performance characteristics of 14 serum protein analytes (alfa 1-antitrypsin, alfa 2-macroglobulin, albumin, apolipoproteins AI and B, C3, C4, haptoglobin, IgA, IgG, IgM, orosomucoid, transferrin and transthyretin) in Roche Cobas C501, they found an excellent correlation between immunonephelometric and immunoturbidimetric assays.

Over the past several decades, numerous commercial autoanalyzers for the measurement of serum proteins have been introduced. Presently, $40 \%$ of laboratories that participate in the College of American Pathologists (CAP) proficiency program use a dedicated nephelometer (source: CAP's 2009 Diagnostic Immunology Survey C). There are, however, a growing number of laboratories who see the adaptation of chemistry analyzers for protein measurement based on immunoturbidimetry, as a logical extension. Our study showed that results of the immunoturbidimetric and immunonephelometric assays for measuring serum b2M levels were highly correlated. It is thought that immunoturbidimetric method of Beckman UniCel DXC 800, can be used safely in the routine screening of serum b2M levels for different types of malignancies. Additionally, using this method can bring many advantages such as rapid turn around time, high volume testing capability and cost reduction for routine clinical laboratories.

\section{References}

1. Vincent C, Revillard JP (1981) Beta-2-microglobulin and HLA-related glycoproteins in human urine and serum. Contrib Nephrol 26: 66-88.

2. Bianchi C, Donadio C, Tramonti G, Consani C, Lorusso P, et al. (2001) Reappraisal of serum beta2-microglobulin as marker of GFR. Ren Fail 23: 419429

3. Strominger JL (2002) Human histocompatibility proteins. Immunol Rev 185 69-77

4. Al-Taee IK, Al-Safar JJ, Al-Falahi YS, Al-Shamma IA (2003) The clinica significance of beta2-microglobulin in end-stage renal disease. Saudi J Kidney Dis Transpl 14: 492-496.

5. Nomura T, Huang WC, Zhau HE, Wu D, Xie Z, et al. (2006) Beta2-microglobulin promotes the growth of human renal cell carcinoma through the activation of the protein kinase A, cyclic AMP-responsive element-binding protein, and vascular endothelial growth factor axis. Clin Cancer Res 12: 7294-7305.

6. Huang WC, Wu D, Xie Z, Zhau HE, Nomura T, et al. (2006) Beta2-microglobulin is a signaling and growth-promoting factor for human prostate cancer bone metastasis. Cancer Res 66: 9108-9116.

7. Mori M, Terui Y, Tanaka M, Tomizuka H, Mishima Y et al (2001) Antitumor effect of beta2-microglobulin in leukemic cell-bearing mice via apoptosis-inducing activity: activation of caspase-3 and nuclear factor-kappaB. Cancer Res 61 : 4414-4417.

8. Min R, Li Z, Epstein J, Barlogie B, Yi Q (2002) Beta(2)-microglobulin as a negative growth regulator of myeloma cells. Brit J Haematol 118: 495-505. 
Citation: Ariyurek SY, Ozturk OG, Kibar F, Ziyanoglu Karacor ED, Sahin G, et al. (2012) Comparison Of Immunonephelometric And Immunoturbidimetric Methods for Measuring Beta 2-Microglobulin: Fit for Purpose in Routine Clinical Laboratories. Biochem Anal Biochem 1:119. doi:10.4172/2161-1009.1000119

9. Gordon J, Wu CH, Rastegar M, Safa AR (2003) Beta2-microglobulin induces caspase-dependent apoptosis in the CCRF-HSB-2 human leukemia cell line independently of the caspase- $3,-8$ and -9 pathways but through increased reactive oxygen species. Int J Cancer 103: 316-327.

10. Faderl S, Keating MJ, Do KA, Liang SY, Kantarjian HM, et al. (2002) Expression profile of 11 proteins and their prognostic significance in patients with chronic lymphocytic leukemia (CLL). Leukemia 16: 1045-1052.

11. Bataille R, Durie BG, Grenier J (1983) Serum beta2 microglobulin and survival duration in multiple myeloma: a simple reliable marker for staging. $\mathrm{Br} J$ Haematol 55: 439-447

12. Abdul M, Hoosein N (2000) Changes in beta-2 microglobulin expression in prostate cancer. Urol Oncol 5: 168-172.

13. Molica S, Levato D, Cascavilla N, Levato L, Musto P (1999) Clinico-prognostic implications of simultaneous increased serum levels of soluble CD23 and beta2-microglobulin in B-cell chronic lymphocytic leukemia. Eur J Haematol 62: $117-122$

14. Bethea M, Forman DT (1990) Beta 2-microglobulin: its significance and clinical usefulness. Ann Clin Lab Sci 20: 163-168.

15. Gatto S, Ball G, Onida F, Kantarjian HM, Estey EH, et al. (2003) Contribution of beta-2 microglobulin levels to the prognostic stratification of survival in patients with myelodysplastic syndrome (MDS). Blood 102: 1622-1625.

16. Nissen MH, Bjerrum OJ, Plesner T, Wilken M, Rorth M (1987) Modification of beta-2-microglobulin in sera from patients with small cell lung cancer: evidence for involvement of a serine protease. Clin Exp Immunol 67: 425-432.

17. Shi C, Zhu Y, Su Y, Chung LW, Cheng T (2009) Beta2-microglobulin: emerging as a promising cancer therapeutic target. Drug Discov Today 14: 25-30.

18. Wiela-Hojenska A, Hurkacz M (1998) The significance of beta 2-microglobulin in diagnosis and therapy. Postepy Hig Med Dosw 52: 507-514.

19. Nishinarita S, Shimada H, Suzuki R, Kishigami Y, Sawada U, et al. (1996) A study of the significance of serum beta 2-microglobulin levels in patients with multiple myeloma--analyzes as a marker of renal dysfunction and as a marker of tumor cell mass. Rinsho Ketsueki 37: 201-207.

20. Hansen PB, Olsen NV (1989) Beta 2-microglobulin in medical disease. Ugeskr Laeger 151: 2960-2962.
21. Mali B, Armbruster D, Serediak E, Ottenbreit T (2009) Comparison of immunoturbidimetric and immunonephelometric assays for specific proteins. Clin Biochem 42: 1568-1571.

22. Sternberg JC (1977) A rate nephelometer for measuring specific proteins by immunoprecipitin reactions. Clin Chem 23: 1456-1464.

23. Hills LP, Tiffany TO (1980) Comparison of turbidimetric and light-scattering measurements of immunoglobulins by use of a centrifugal analyzer with absorbance and fluorescence/light-scattering optics. Clin Chem 26: 1459-1466.

24. Blirup-Jensen S (2001) Protein standardization III: Method optimization basic principles for quantitative determination of human serum proteins on automated instruments based on turbidimetry or nephelometry. Clin Chem Lab Med 39 1098-1109.

25. Ledue TB, Collins MF (2011) Development and Validation of 14 Human Serum Protein Assays on the Roche cobass ${ }^{\circledR}$ c 501. J Clin Lab Anal 25: 52-60.

26. Whicher J, Johnson M (2001) The present state of protein analysis and interpretation. Clin Chem Lab Med 39: 1017-1018.

27. De BK, Jimenez E, De S (2009) Performance characteristics of beta-2 microglobulin measurements on a Beckman Immage analyzer with the DakoCytomation reagent kit. Clin Biochem 42: 1577-1581.

28. Correia LC, Lima JC, Gerstenblith G, Magalhães LP, Moreira A, et al. (2003) Correlation between turbidimetric and nephelometric methods of measuring $\mathrm{C}$-reactive protein in patients with unstable angina or non-ST elevation acute myocardial infarction. Arq Bras Cardiol 81: 133-136.

29. Denham E, Mohn B, Tucker L, Lun A, Cleave P, et al. (2007) Evaluation of immunoturbidimetric specific protein methods using the Architect ci8200: comparison with immunonephelometry. Ann Clin Biochem 44: 529-536.

30. Dominici R, Luraschi P, Franzini C (2004) Measurement of C-reactive protein: two high sensitivity methods compared. J Clin Lab Anal 18: 280-284.

31. Liu R, Li G, Cui XF, Zhang DL, Yang QH, et al. (2011) Methodological evaluation and comparison of five urinary albumin measurements. J Clin Lab Anal 25: 324 329 .

32. Siedel J, Schiefer S, Rosseneu M, Bergeaud R, De Keersgieter W, et al. (1988) Immunoturbidimetric method for routine determinations of apolipoproteins A-I, A-II, and B in normo- and hyperlipemic sera compared with immunonephelometry. Clin Chem 34: 1821-1825. 